\title{
Sylvie Chalaye (dir.), Le théâtre de Kossi Efoui: une poétique du marronnage
}

\section{Gianni Poli}

\section{Q OpenEdition}

1 Journals

\section{Edizione digitale}

URL: http://journals.openedition.org/studifrancesi/3901

DOI: 10.4000/studifrancesi.3901

ISSN: 2421-5856

\section{Editore}

Rosenberg \& Sellier

\section{Edizione cartacea}

Data di pubblicazione: 1 décembre 2012

Paginazione: 622

ISSN: 0039-2944

\section{Notizia bibliografica digitale}

Gianni Poli, «Sylvie Chalaye (dir.), Le théâtre de Kossi Efoui: une poétique du marronnage», Studi Francesi [Online], 168 (LVI | III) | 2012, online dal 30 novembre 2015, consultato il 05 mars 2021. URL: http:// journals.openedition.org/studifrancesi/3901 ; DOI: https://doi.org/10.4000/studifrancesi.3901

Questo documento è stato generato automaticamente il 5 mars 2021.

\section{(c) (i) $\odot$}

Studi Francesi è distribuita con Licenza Creative Commons Attribuzione - Non commerciale - Non opere derivate 4.0 Internazionale. 


\title{
Sylvie Chalaye (dir.), Le théâtre de Kossi Efoui: une poétique du marronnage
}

\author{
Gianni Poli
}

\section{NOTIZIA}

SYLVIE CHALAYE (dir.), Le théâtre de Kossi Efoui: une poétique du marronnage, «Africultures», 86, 2011, pp. 248.

1 La presenza diffusa e affermata in Francia di drammaturghi africani francofoni continua a suscitare interesse, nel rinnovamento dell'espressione teatrale contemporanea e nella moltiplicazione dei punti di vista sulle realtà socio-culturali rappresentate. Instancabile in questo settore d'indagine, Sylvie Chalaye, docente alle Università di Rennes e di Parigi, raccoglie ora un Dossier dedicato all'autore togolese Koffi Efoui. Questa raccolta di saggi, interviste, testimonianze e illustrazioni di spettacoli, ne conferma l'importanza artistica crescente per il vasto pubblico francese, oltre che presso gli specialisti. Il volume è suddiviso in quattro parti tematiche (a ciascuna delle quali s'affianca una Tavola rotonda): I - «Rupture et subversion»; II - «Exil et errance»; III - «Rythme, corps et voix»; IV - «Un théâtre de l'envol». Nelle diverse sezioni si analizzano le caratteristiche potenzialità di singole pièces, dall'esordio di Le Carrefour (1989) alle ultime Oublie! e Le Choix des Ancêtres (2011). L'inquadramento nell'insolita peculiare costante del «marronnage», è segnalato in un'intervista del 2004, qui ripresa da Boldwenn MAUFFRET nel suo articolo sulla nascita del drammaturgo. La coordinatrice sintetizza così i risultati del lavoro svolto all'IRET (Institut Recherche Études Théâtrales) all'Université Sorbonne Nouvelle-Paris 3 e nel Colloque Kossi Efoui del 2010: «Objet Volatile Non Identifié, son théâtre marronne, donne sans cesse rendezvous ailleurs pour mieux mettre en crise le spectateur. Ses personnages ne sont pas identifiables, ils muent, changent de peaux, perdent une à une leurs pelures comme les 
oignons» (p. 9). E nell'intervento conclusivo, Caya MAKHÉLÉ rileva: «La francophonie est justement un bel espace de marronnage... C'est un espace qui nous permet d'avoir plusieurs visages, de porter le masque du théâtre et d'arriver en dansant une rumba effrenée tout en pensant à Baudelaire» (p. 246). 